\title{
$\mathrm{OFDM}$ 신호에 대한 스펙트럼 센싱 기술
}

\section{Spectrum Sensing Technique for OFDM Signals}

\author{
배한석 · 김영식* $\cdot$ 임창헌 ${ }^{* \star} \cdot$ 김창주 ${ }^{*} \cdot$ 조윤석* \\ Han-Seok Bae · Young-Sik Kim* • Chang-Heon Lim** $\cdot$ Chang-Joo Kim* · Yoon-Seok Cho*
}

요 약

본 논문은 기계학습에 기반을 둔 $\mathrm{OFDM}$ 신호를 탐지하는 알고리즘을 개발한 결과다. 스펙트럼 탐지 기술은 주파수 자원을 효율적으로 이용할 수 있는 인지 무선통신의 핵심 기술이다. 최근 무선통신시스템에서 송수신되는 신호는 OFDM 을 기반으로 하고 있다. OFDM 신호는 채널 보정을 위해 파일럿 신호를 포함하고 있는데, 스펙트럼 상관 함수(SCF)를 사용하여 이를 검출할 수 있다. 이 과정에서 효율적인 SCF 연산을 위해 FAM 알고리즘이 사용되었다. 이렇게 구한 SCF 를 입력 데이터로 하는 $\mathrm{CNN}$ 신경망 방식의 기계학습 알고리즘을 통해 $\mathrm{OFDM}$ 신호의 유무를 판단한다. 기계학습을 위한 학습 데이터는 $-20 \mathrm{~dB} \sim 0 \mathrm{~dB}$ 의 SNR을 갖는 OFDM 신호의 SCF 값이 사용되었다. 학습 후 최적화한 신경망의 성능을 평가한 결과, $\mathrm{SNR}$ 이 $-12 \mathrm{~dB}$ 인 수신 신호에 대해 오경보 확률 0.08 조건에서 0.9 확률로 신호를 탐지하였다.

Abstract

This paper presents a machine learning (ML) algorithm to detect orthogonal frequency-division multiplexing (OFDM) signals. Spectrum sensing is a key technology in cognitive radio communication, which enhances spectral efficiency. Recently, signals transmitted and received by wireless communication systems have been based on OFDM. These signals contain a pilot signal for channel calibration, which can be detected using a spectral correlation function (SCF). In this process, the FAM algorithm is applied for efficient SCF operation herein. The existence of OFDM signals is determined through a convolutional neural network-based ML algorithm using the SCF as input data. The learning data for ML use the SCF values for OFDM signals with signal-to-noise ratios (SNRs) of -20 to $0 \mathrm{~dB}$. Consequently, on evaluation of the post-learning optimized neural network performance, signals were detected with a probability of 0.9 at the condition of 0.08 false alarm probability for reception signals with SNRs of $-12 \mathrm{~dB}$.

Key words: OFDM, Cyclostationary, Spectral Correlation Function, FFT Accumulation Method, CNN

\section{I. 서 론}

최근 무선 통신수요가 증가함에 따라 주파수 고갈 문 제 해결을 위한 많은 연구가 진행되었다 ${ }^{[1]-[4]}$. 이러한 문

\footnotetext{
「이 논문은 2020년도정부(과학기술정보통신부)의 재원으로 정보통신기획평가원의 지원을 받아 수행된 연구임 (2019-0-00964, 스펙트럼 챌린지를 통 한 기존 무선국 보호 및 주파수 공유기술 개발).」

「이 논문은 2020 년도 한동대학교의 연구년 지원에 의하여 작성되었음. 한동대학교 정보통신공학과(Department of Information Communicationl Engineering, Handong University) *한동대학교 전산전자공학부(School of Computer Science and Electrical Engineering, Handong University)

**부경대학교 전자공학과(Department of Electronics Engineering, Pukyong University)

- Manuscript received November 16, 2020 ; Revised November 22, 2020 ; Accepted December 7, 2020. (ID No. 20201116-010S)

· Corresponding Author: Young-Sik Kim (e-mail: young@handong.edu)
} 
THE JOURNAL OF KOREAN INSTITUTE OF ELECTROMAGNETIC ENGINEERING AND SCIENCE. vol. 32, no. 1, January. 2021.

제를 해결하기 위한 대표적인 기술인 동일대역 전이중 통신 방식에 관한 연구도 활발히 진행되었다라. 그러나 참고문헌 [2]에서 제시된 전이중 통신 기술은 송신과 수 신을 동시에 동일대역에서 수행하기 위해 송신 자기 간 섭 신호를 제거하는 것이 필수적이다.

최근 다른 대안으로 유력하게 부상하고 있는 기술이 인지 무선(CR: cognitive radio)이다 ${ }^{[1],[3],[4]}$. 인지 무선의 핵 심적인 개념은 우선 사용자(PU: primary user)가 국지적 혹은 일시적으로 사용하지 않는 주파수 대역을 검출하여 특정 조건에서 사용하는 기술이다. CR 방식에서 핵심 기 술은 사용하고자 하는 주파수 대역을 우선 사용자가 점 유 중 인지를 검출하는 스펙트럼 센싱(spectrum sensing) 기술이다 ${ }^{[1]}$. 그리고 $\mathrm{OFDM}$ (orthogonal frequency division multiplexing)은 대역 효율이 우수한 기술로, 최근 무선 통 신에서 이를 광범위하게 사용하고 있기 때문에 인지 무 선 시스템 구현에서 $\mathrm{OFDM}$ 신호를 검출하는 것은 매우 중요하다. 대표적인 $\mathrm{OFDM}$ 신호 검출 방식은 $\mathrm{OFDM}$ 신 호 자체가 갖는 $\mathrm{CP}$ (cyclic prefix)를 통해 각 구간 간의 상 관성을 이용하는 방식과, $\mathrm{OFDM}$ 신호의 보정을 위해 삽 입하는 파일럿 톤을 감지하는 방법이 있다 ${ }^{[4],[5]}$. 하지만 이 기술들은 낮은 $\mathrm{SNR}$ 조건에서 스펙트럼 센싱 성능이 떨어 진다.

본 연구에서는 OFDM 신호의 특징인 파일럿 톤을, 신 호의 주기적 정상성(cyclostationary) 특징에 속하는 스펙 트럼 상관 함수(SCF: spectral correlation function)를 통해 특징을 추출하고, 이를 $\mathrm{ML}$ (machine learning) 방식과 결합 하여 낮은 $\mathrm{SNR}$ 조건에서 $\mathrm{PU}$ 의 $\mathrm{OFDM}$ 신호를 검출하는 스펙트럼 센싱 기술을 개발하고 성능을 평가하였다.

\section{II. 스펙트럼 센싱 모델 및 주기적 정상성 분석}

\section{2-1 스펙트럼 센싱 가설 검정}

스펙트럼 센싱은 이차 사용자(SU: secondary user)가 수 신한 신호를 통해 PU의 신호의 유무를 판별하는 과정이 다. $r(t)$ 를 $\mathrm{SU}$ 가 수신한 신호라 할 때, 식 (1)에서 $\mathrm{PU}$ 신 호가 없는 $H_{0}$ 의 경우, 가산 백색 가우스 잡음(AWGN: additive white Gaussian noise) $w(t)$ 만 수신된다. PU 신호 가 있는 $H_{1}$ 의 경우, $\mathrm{PU}$ 의 신호 $(s(t))$ 가 채널 $(h(t))$ 를 통

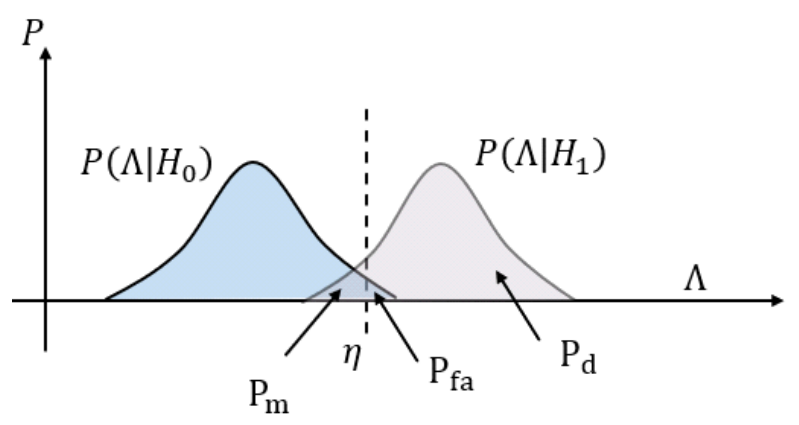

그림 1. 검정통계량 그래프

Fig. 1. Test statistic graph.

과하면서 다중경로 페이딩 효과(multi-path fading effect)와 AWGN가 적용된 수신 신호를 나타낸다.

$$
\begin{aligned}
& H_{0}: r(t)=w(t) \\
& H_{1}: r(t)=h(t) \otimes s(t)+w(t)
\end{aligned}
$$

$\mathrm{PU}$ 신호의 유무 $\left(H_{1}, H_{0}\right)$ 에 대한 가설 검정은 $\mathrm{SU}$ 가 수 신한 신호의 주기적 정상성 특징인 $\mathrm{SCF}$ 를 이용한 검정 통계량을 사용하였다. 그림 1은 신호 유무에 따른 검정 통계량의 확률분포를 나타낸다. 검정 통계량 $\Lambda$ 가 임계값 $\eta$ 보다 크면 신호가 존재하는 것으로 판정한다.

신호 센싱에 대한 가설 검정 지표로, $\mathrm{PU}$ 신호가 있을 때 이를 검파할 확률 $\left(P_{d}\right.$ : detection probability)과 신호가 없을 때 신호가 있다고 판단할 오경보 확률 $\left(P_{f a}\right.$ : false alarm probability)을 식 (2)에 정의했다. 식 (2)에서 $\Lambda$ 는 검 정 통계량을 나타내고, $\eta$ 는 검정 통계량의 임계값이다. 미탐지 확률 $\left(P_{m}\right.$ : probability of miss-detection)은 $1-P_{d}$ 를 나타낸다.

$$
\begin{aligned}
P_{d} & =P\left(\Lambda>\eta \mid H_{1}\right) \\
P_{f a} & =P\left(\Lambda>\eta \mid H_{0}\right)
\end{aligned}
$$

\section{2-2 주기적 정상성 특징을 이용한 SCF 계산}

주기적 정상성을 가지는 신호의 경우, 자기 상관관계 함 수(ACF: auto-correlation function)가 주기 $T$ 를 가진다. 따라 서 $\mathrm{ACF}$ 를 식 (3)처럼 Fourier series로 표현할 수 있다[6].

$$
R_{x}(t, \tau)=\sum_{\alpha} R_{x}^{\alpha}(\tau) e^{j 2 \pi \alpha t}
$$

식 (3)에서 $R_{x}^{\alpha}(\tau)$ 는 순환 자기상관 함수(CAF: cyclic 
auto-correlation function)로, 식 (4)와 같이 정의된다미.

$$
R_{x}^{\alpha}(\tau)=\frac{1}{T} \int_{T} R_{x}(t, \tau) e^{-j 2 \pi \alpha t} d t
$$

식 (3), 식 (4)에서 $\alpha$ 는 순환 주파수(cyclic frequency) 로, 주기 $T$ 의 체배 주파수(harmonic frequency)고, $\tau$ 는 자 기 상관 신호의 시간 차이를 나타낸다. 그리고 스펙트럼 상관 함수(SCF)는 신호의 주기적 정상성 특징으로, 서로 다른 주파수 성분 간의 유사성 정도를 나타내고, 식 (5)와 같이 정의된다 ${ }^{[6]}$.

$$
S_{x}^{\alpha}(f)=\int_{-\infty}^{\infty} R_{x}^{\alpha}(\tau) e^{-2 \pi f \tau} d \tau
$$

$\mathrm{SCF}$ 를 구하는 방법은 먼저 $x(t)$ 신호를 일정 시간 $T_{L}$ 씩 이동하면서 시간 구간 $T_{N}$ 인 신호를 $N$ 개로 샘플링하 여 시간과 주파수에 영역의 Periodogram $X_{T_{W}}(n, f)$ 을 식 (6)으로 구한다.

$$
X_{T_{W}}(n, f)=\sum_{k=0}^{N^{\prime}-1} g(k) x(n-k) e^{-j 2 \pi f(n-k)}
$$

다음으로 서로 다른 두 주파수 $f_{1}=f+\alpha / 2$ 와 $f_{2}=f-\alpha / 2$ 사 이의 상관관계인 SCF를 식 (7)과 같이 얻을 수 있다[7].

$$
\begin{aligned}
S_{x x}^{\alpha}(f)= & \lim _{\substack{N \rightarrow \infty \\
N}} \frac{1}{2 N+1} \\
& \sum_{n=-N}^{N} X_{T_{W}}\left(n, f+\frac{\alpha}{2}\right) \cdot X_{T_{W}}^{*}\left(n, f-\frac{\alpha}{2}\right)
\end{aligned}
$$

$\mathrm{SCF}$ 를 계산하기 위해선 많은 연산과정이 필요하다. $\mathrm{SCF}$ 를 효율적으로 구할 수 있는 여러 알고리즘 중에 FAM(FFT accumulation method)과 SSCA(strip spectral correlation)가 있다 ${ }^{[7]-[9]}$. 본 연구에서는 FAM 방식을 이용 하여 SCF를 계산하였다. FAM 방식은 샘플링 주파수가 $f_{s}\left(=\frac{1}{T_{s}}\right)$ 일 때, 그림 2 와 같은 $N$ 개의 입력 신호를 $T_{L}$ 샘 플씩 이동하면서 $N^{\prime}$ 개의 구간을 가지는 $P+1$ 개의 샘플을 구한다.

다음으로 그림 3 과 같이 각 구간의 샘플을 그림 2의 수 평 방향으로 $N^{\prime}$-FFT를 통해 주파수 영역으로 변환한 후 기저대역 신호로 주파수 변환을 수행한다. 이후 서로 다 른 주파수 신호의 상관관계를 그림 2에서 수직인 $P$ 방향

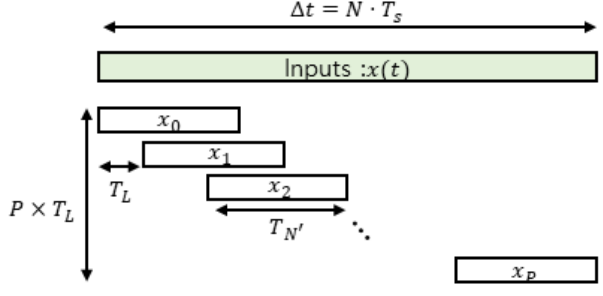

그림 2. 입력 세그먼트

Fig. 2. Input segmentation.

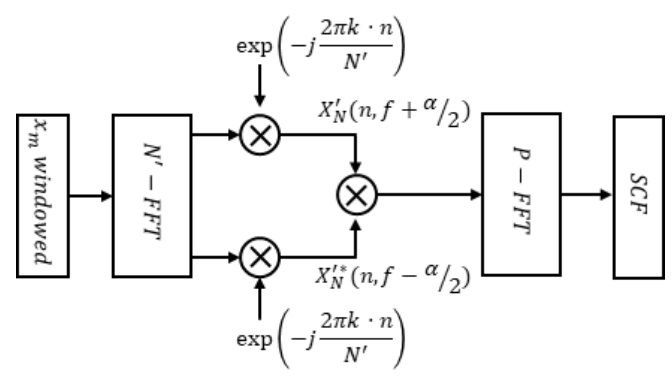

그림 3. FAM 방식 스펙트럼 상관관계 연산

Fig. 3. Spectral correlation with FAM.

으로 연산한 후, P-FFT를 수행하면 SCF를 구할 수 있다.

$\mathrm{SCF}$ 에서 주파수 분해능은 샘플링 주파수 $f_{s}$ 인 경우, $\Delta f=f_{s} / N^{\prime}$ 으로 주어진다. $T_{L}=L / f_{s}$ 은 연산량과 순환 주파수 누출(cyclic frequency leakage)를 고려하여 $\mathrm{L}=N^{\prime} / 4$ 을 값 사용한다. 그리고 $P$ 의 값은 순환 주파수의 분해능 $\Delta \alpha=f_{s} / P / L$ 을 고려하여 결정한다.

\section{2-3 OFDM 신호의 SCF 결과}

SCF 특성을 실험하기 위해 802.11a 표준 OFDM 신호 는 $64 \mathrm{FFT}$ 를 이용하였다. 이 신호는 64개의 부 반송파 (sub-carrier) 중에 DC와 보호대역을 위한 12 개를 제외하 고 52 개의 부 반송파를 사용한다. 그리고 채널 보정과 동 기화 목적으로 4 개의 파일럿 신호를 사용한다. 파일럿 부 반송파 채널은 $-21,-7,7,21$ 이며, 파일럿 신호의 값은 표준 스크램블러를 이용하여 생성한다. 48 개의 부 반송파 에는 무작위 데이터를 생성하고, $64 \mathrm{QAM}$ 방식으로 변조 한 후 IFFT를 이용하여 시간 영역의 신호를 생성하였다.

MATLAB 환경에서 SNR $10 \mathrm{~dB}$ 의 802.11a 신호를 생성 한 후 해당 신호에 FAM 연산을 적용해 SCF를 구했다. 하 


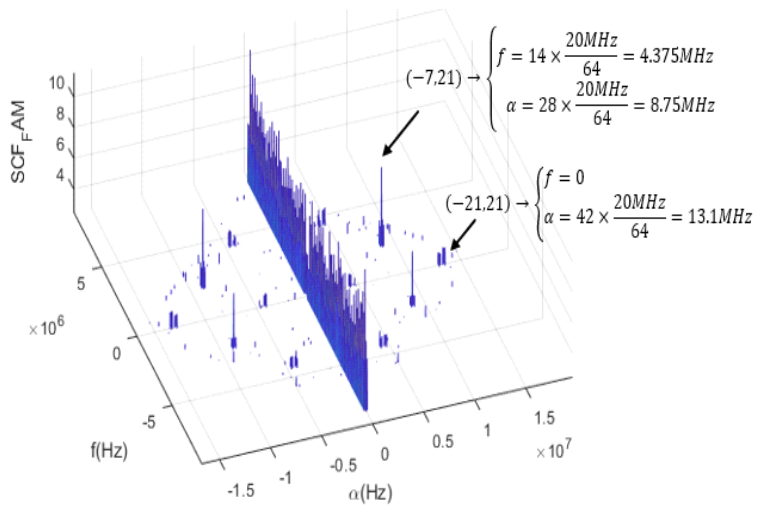

그림 4. $\mathrm{FAM}$ 으로 구한 $\mathrm{SC}$

Fig. 4. SC operated with FAM.

나의 OFDM 심볼에는 48 개의 서로 상관관계가 없는 부 반송파와 상관 관계가 존재하는 4 개의 파일럿 신호가 실 려 있으므로, $\mathrm{SCF}$ 에는 파일럿 신호의 특징이 포함된다.

그림 4는 $\mathrm{SNR}$ 이 $10 \mathrm{~dB}$ 인 $\mathrm{OFDM}$ 수신신호(802.11a 신 호)에 $\mathrm{FAM}$ 연산으로 $\mathrm{SCF}$ 를 구한 결과를 그래프로 나타 냈다. 그림 4에서 순환 주파수 $\alpha=0$ 일 때인 $S_{x x}^{0}(f)$ 는 수 신 신호의 전력 스펙트럼 밀도(power spectral density)를 나타낸다. 그리고 그림에서 12 개의 극값을 가지는 위치는 파일럿 신호의 상관관계를 나타낸다. 예를 들어 -7 과 21 채널 두 파일럿 신호의 스펙트럼 상관함수 값이 존재하 는 주파수와 순환 주파수 위치는 식 (8)과 같이 주어진다.

$$
\begin{aligned}
& f=\frac{21-7}{2} \times \frac{20 \mathrm{MHz}}{64}=4.38 \mathrm{MHz} \\
& \alpha=21+7 \times \frac{20 \mathrm{MHz}}{64}=8.75 \mathrm{MHz}
\end{aligned}
$$

$\mathrm{SCF}$ 가 극값을 가지는 파일럿 채널 쌍을 구하면 그림 4 와 같이 12 개의 극점이 나타나게 되며, 이는 SCF를 이용 해 OFDM 신호의 파일럿 특징을 검출할 수 있음을 의미 한다.

\section{III. 기계학습을 이용한 신호 검출 및 결과 분석}

앞서 제안한 SCF를 이용하여 $\mathrm{OFDM}$ 신호를 검출하는 기계학습 기반 신호 검출 알고리즘을 구현하였다. 학습을 위해 신호의 $\mathrm{SNR}$ 값이 $0 \mathrm{~dB}$ 에서 $-20 \mathrm{~dB}$ 범위를 가지는 $\mathrm{OFDM}$ 신호를 각각 2,000 개씩 생성하였다. 각 신호들의
샘플은 80 개의 OFDM 심볼로 구성되며, 샘플링 주파수는 $20 \mathrm{MHz}$ 이다. 신호 생성 과정에서 송수신 과정에 채널에 서 발생하는 다중 경로 페이딩 효과와 반송파 주파수 편 차(carrier frequency offset)도 고려한다. 이 신호에서 SCF 를 구한 후 SCF 데이터셋을 $64 \times 64$ 크기로 정규화(normalize)하여 ML입력으로 사용하였다.

$\mathrm{ML}$ 에서 RNN(recurrent neural network), 그리고 $\mathrm{CNN}$ (convolutional neural network)과 같은 인공신경망들은 최 근 다양한 분야에서 사용되고 있다. $\mathrm{RNN}$ 은 문자, 음성과 같은 순차적인 데이터를 처리하는 신경망으로, 데이터가 입력될 때마다 히든 유닛(hidden units)의 내용을 갱신하 면서 순차적 데이터를 요약한다. 음성인식, 자동 번역 분 야에서 많이 응용되는 모델이다 ${ }^{[10],[1]]}$. CNN은 이미지, 비 디오, 텍스트 등을 분류할 때 사용하는 인공신경망으로, 여러 개의 필터를 거쳐 입력 데이터로 사용되는 이미지 의 특징들을 파악하고 학습을 진행한다 ${ }^{[12]}$.

검출 대상이 되는 $\mathrm{OFDM}$ 신호의 파일럿 신호가 주기 적 정상성을 갖기 때문에, 신호의 $\mathrm{SC}$ 값을 이미지 형태로 배열하면 반복적인 패턴으로 나타난다. 따라서 이미지 데 이터가 갖는 동일한 패턴으로 대상을 분류(classification) 하기 위해 $\mathrm{ML}$ 에 적용하기 적합한 인공신경망은 $\mathrm{CNN}$ 방 식이고, 시뮬레이션을 진행할 때 사용한 신경망 구조는 그림 5와 표 1에 나타내었다.

인공신경망 모델의 입력은 $64 \times 64$ 로 재구성된 2차원 $\mathrm{SCF}$ 값이며, 2 개의 컨볼루션 레이어와 $2 \times 2$ 커널 크기로

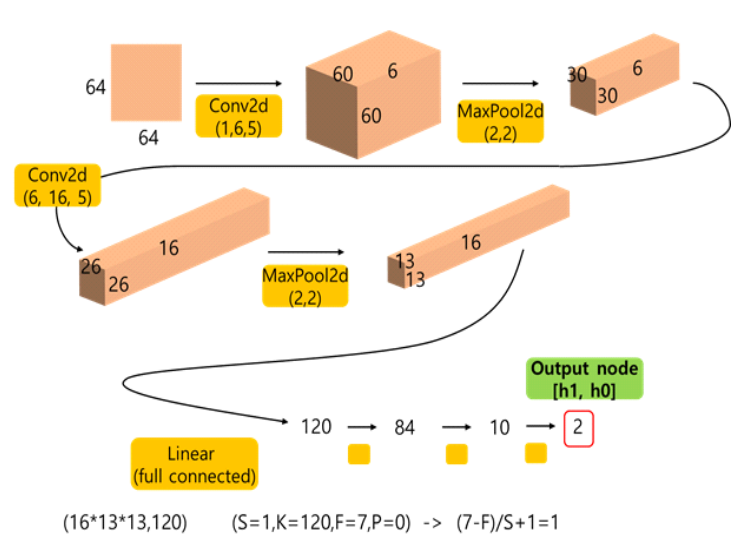

그림 5. 인공신경망 모델

Fig. 5. Neural network model. 
표 1. 신경망 구조

Table 1. Neural net structure.

\begin{tabular}{|c|c|}
\hline \multicolumn{2}{|c|}{ Input: SCF ( Dim= $64 \times 64$ ) } \\
\hline Layers & Kernel size \\
\hline$C_{1} /$ ReLU & $1 \times 6 \times(5 \times 5)$ \\
\hline$S_{1}$ (max-pool) & $2 \times 2$ \\
\hline$C_{2} / \operatorname{ReLU}$ & $6 \times 16 \times(5 \times 5)$ \\
\hline$S_{2}$ (max-pool) & $2 \times 2$ \\
\hline$F_{1} / \operatorname{ReLU}$ & $2,074 \times 120$ \\
\hline$F_{2} / \operatorname{ReLU}$ & $120 \times 84$ \\
\hline$F_{3} / \operatorname{ReLU}$ & $84 \times 10$ \\
\hline$F_{4} /$ softmax & $10 \times 2$ \\
\hline \multicolumn{2}{|c|}{ Output: $\left[h_{0}, h_{1}\right]$ ( 2D-array ) } \\
\hline \multicolumn{2}{|c}{} \\
\hline
\end{tabular}

풀링(pooling)을 수행한다. 풀링 이후에는 4개의 완전연결 신경망(fully connected layer)이 사용되었다. 활성 함수로 는 ReLU(rectified linear unit)가 사용되었으며, 마지막 신 경망의 경우, 출력 결과 값이 확률 값이 되도록 Softmax 활성 함수가 사용되었다.

학습을 위한 데이터의 레이블은 $\left[h_{0}, h_{1}\right]$ 의 2 차원 벡터 로 신호가 존재하는 경우 $[1,0]$, 반면 신호가 존재하지 않 는 경우 $[0,1]$ 값이 사용된다. 이는 학습 과정에서 신호가 존재하는 경우 $h_{1}=1, h_{0}=0$ 으로 수렴하고, 신호가 없는 경 우를 $h_{1}=0, h_{0}=1$ 로 수렴하도록 학습한다. 최종 신경망의 활성 함수로 Softmax가 사용되는 경우, 출력 벡터의 $h_{0}$ 는 신호가 없을 확률을, 그리고 $h_{1}$ 은 신호가 존재할 확률을 각각 나타낸다. 따라서 항상 $h_{0}+h_{1}=1$ 을 만족한다. 그림 6

Loss

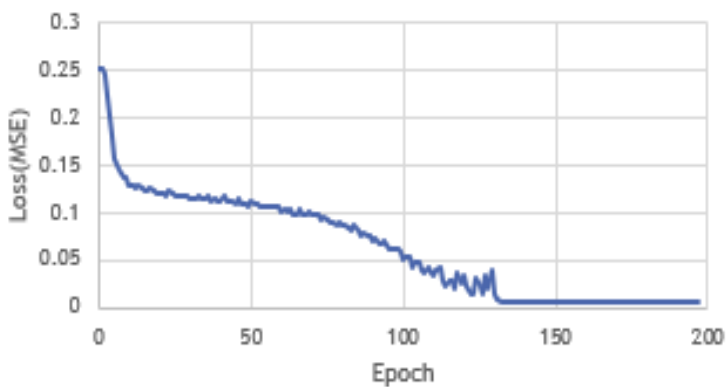

그림 6. 손실 그래프

Fig. 6. Loss graph.
은 학습 과정의 손실 값을 나타내며, 150 Epoch 이후 수 렴되는 것을 알 수 있다.

인공신경망의 학습이 완료된 후, 최적화 된 신경망을 이용하여 성능 평가를 수행하였다. 주어진 각 SNR에서 2,000 개 데이터 세트를 이용하여 신호 유무를 판정하였 다. 이 때 사용된 검정 통계량으로 식 (9)을 사용하였다.

$$
\Lambda=h_{1}-h_{0}
$$

그림 7은 $\mathrm{SNR}$ 에 따른 오경보 확률 $P_{f a}$ 와 탐지 확률 $P_{d}$ 의 상충관계를 나타낸다. $0 \mathrm{~dB},-3 \mathrm{~dB},-6 \mathrm{~dB},-7 \mathrm{~dB},-$ $10 \mathrm{~dB}$ 인 경우(실선), 모두 유사한 성능을 나타내고 있다. $-12 \mathrm{~dB}$ 부터는 SNR에 따라 탐지 확률의 차이가 나타남을 확인할 수 있다. $\mathrm{SNR}$ 이 $-18 \mathrm{~dB}$ 인 경우, 오경보 확률 $P_{f a}$ 가 0.2 일 때 탐지 확률 $P_{d}$ 가 0.4 임을 확인할 수 있다.

그림 8 은 본 논문에서 진행한 센싱 기술을 적용하였을

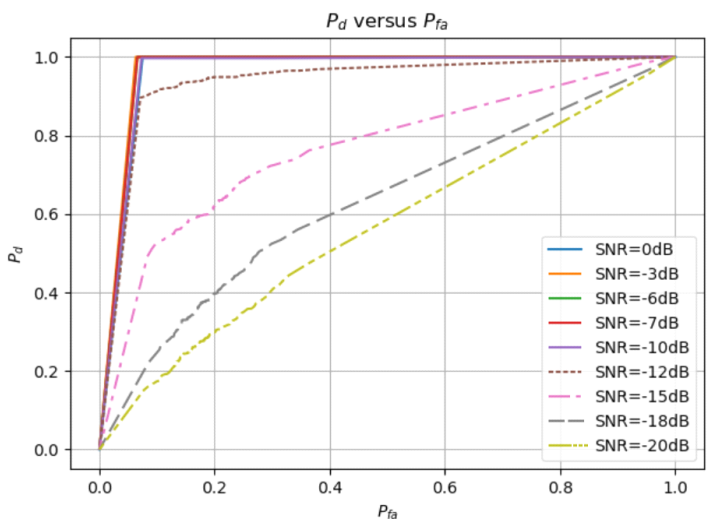

그림 7. 오경보 확률에 따른 감지 확률 그래프 Fig. 7. Graph of $P_{d}$ versus $P_{f a}$.

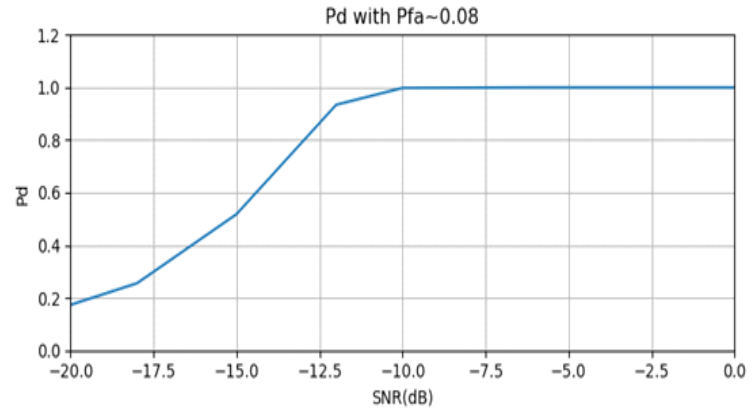

그림 8. SNR에 따른 신호 탐지 확률

Fig. 8. Probability of signal detection versus SNR. 
때, 오경보 확률 $P_{f a}$ 값이 0.08 인 경우, $\mathrm{SNR}$ 에 따른 탐지 확률을 나타낸다. $\mathrm{SNR}$ 이 $-12 \mathrm{~dB}$ 일 때, 탐지 확률 $P_{d}$ 값 이 0.9 가 됨을 확인할 수 있다.

기계학습을 활용한 스펙트럼 센싱은 최근 활발히 연구 되고 있다. 참고문헌 [13]과 [14]는 다른 기계학습 알고리 즘을 이용하여 $\mathrm{OFDM}$ 신호를 검출한 결과를 보여준다. 참고문헌 [13]과 [14]에서 제시된 ML을 이용한 두 가지 검출 방식은 기존의 센싱 방식인 에너지 검파, 공분산 행 렬을 이용한 방식보다 성능이 우수함을 제시한다. SNR이 $-12 \mathrm{~dB}$, 오경보 확률 $P_{f a}$ 이 0.05 인 경우, 딥러닝을 이용 한 참고문헌 [13] 방식의 탐지 확률 $P_{d}$ 는 0.55 , 그리고 참 고문헌 [14]가 제시한 방식의 경우 $P_{d}$ 는 약 0.9 다. 이는 동일 조건에서 에너지 검파의 $P_{d}$ 는 0.3 , 공분산 행렬을 이용한 센싱 방식의 $P_{d}$ 는 0.2 인 것에 비에 더 나은 성능 을 나타냄을 알 수 있다.

\section{IV. 결 론}

본 연구에서는 전파신호의 $\mathrm{SCF}$ 와 $\mathrm{ML}$ 을 이용해, 인지 무선통신 구현에 필수적인 스펙트럼 검출을 연구하였다. 검출 대상 전파신호는 $802.11 \mathrm{a}$ 표준의 $\mathrm{OFDM}$ 신호를 이 용하였고, $\mathrm{SCF}$ 를 이용하여 $\mathrm{OFDM}$ 심볼에 포함된 파일럿 신호를 검출할 수 있음을 제시하였다. 그리고 $\mathrm{SCF}$ 를 입 력으로 하는 인공신경망을 이용하여 스펙트럼 검출 알고 리즘을 구현하였다. 스펙트럼 검출 성능 평가를 위해 입 력 신호의 SNR이 $-20 \mathrm{~dB} \sim 0 \mathrm{~dB}$ 범위를 가지는 학습 신 호와 평가 신호를 생성하였다. 학습 단계를 통해 신경망 을 최적화하고, 최적화한 신경망을 이용하여 평가 신호를 검출하였다. 평가 결과, 오경보 확률 $P_{f a} 0.08$ 에서 $\mathrm{SNR}$ 이 $-12 \mathrm{~dB}$ 의 신호를 탐지할 확률 $P_{d}$ 가 0.9 이상 되는 결과를 얻을 수 있었고, 기존의 센싱 기술로 제시된 에너지 검파, 공분산 행렬 추출 방식보다 낮은 $\mathrm{SNR}$ 에서 더 나은 센싱 성능을 보임을 확인할 수 있었다.

\section{References}

[1] H. S. Bae, Y. S. Kim, C. H. Lim, C. J. Kim, and Y. S. Cho, "Spectrum sensing technology for OFDM signals," in 2020 The Korean Institute of Electromagnetic Engine- ering and Science(KIEES) Summer Conference, Jeju, 2020, p. 439.

[2] H. E. Park, J. Yoon, and Y. Kim, "In-band full-duplex wireless communication using USRP," The Journal of Korean Institute of Electromagnetic Engineering and Science, vol. 30, no. 3, pp. 229-235, Mar. 2019.

[3] T. Yucek, H. Arslan, "A survey of spectrum sensing algorithms for cognitive radio applications," IEEE Communications Surveys \& Tutorials, vol. 11, no. 1, pp. 116130, 2009.

[4] D. Cabric, S. M. Mishra, and R. W. Brodersen, "Implementation issues in spectrum sensing for cognitive radios," in Conference Record of the Thirty-Eighth Asilomar Conference on Signals, Systems and Computers, Pacific Grove, CA, Nov. 2004, vol. 1, pp. 772-776.

[5] S. Chaudhari, V. Koivunen, and H. V. Poor, "Autocorrelation-based decentralized sequential detection of OFDM signals in cognitive radios," IEEE Transactions on Signal Processing, vol. 57, no. 7, pp. 2690-2700, Jul. 2009.

[6] C. M. Spooner, W. A. Gardner, "The cumulant theory of cyclostationary time-series, Part I: Foundation," IEEE Transactions on Signal Processing, vol. 42, no. 12, pp. 3387-3408, Dec. 1994.

[7] R. S. Roberts, W. A. Brown, and H. H. Loomis, "Computationally efficient algorithms for cyclic spectral analysis," IEEE Signal Processing Magazine, vol. 8, no. 2, pp. 38-49, Apr. 1991.

[8] C. M. Spooner, W. A. Gardner, "The cumulant theory of cyclostationary time-series, Part II: Development and applications," IEEE Transactions on Signal Processing, vol. 42, no. 12, pp. 3409-3429, 1994.

[9] W. Gardner, L. Franks, "Characterization of cyclostationary random signal processes," IEEE Transactions on Information Theory, vol. 21, no. 1, pp. 4-14, Jan. 1975.

[10] J. L. Elman, "Finding structure in time," Cognitive Science, vol. 14, no. 2, pp. 179-211, 1990.

[11] Y. Wu, M. Schuster, Z. Chen, Q. V. Le, M. Norouzi, and W. Macherey, et al., "Google's neural machine translation system: Bridging the gap between human and 
machine translation," 2016. Available: https://arxiv.org/ abs/1609.08144

[12] A. Krizhevsky, I. Sutskever, and G. E. Hinton, "ImageNet classification with deep convolutional neural networks," Communications of the ACM, vol. 60, no. 6, pp. 84-90, May 2017.

[13] M. R. Vyas, D. K. Patel, and M. Lopez-Benitez, "Artificial neural network based hybrid spectrum sensing scheme for cognitive radio," in 2017 IEEE 28th

\section{배 한 석 [한동대학교/석사과정]}

https://orcid.org/0000-0002-6493-7914

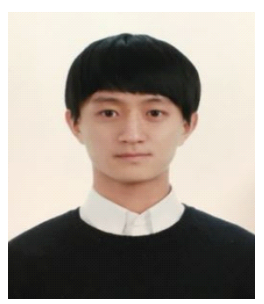

2019년 2월: 한동대학교 전산전자공학부 (공학사)

2019년 2월 현재: 한동대학교 정보통신 공학과 석사과정

[주 관심분야] 무선통신시스템, 머신러닝, 신호처리, 스펙트럼

김 영 식[한동대학교/교수]

https://orcid.org/0000-0003-1590-8233

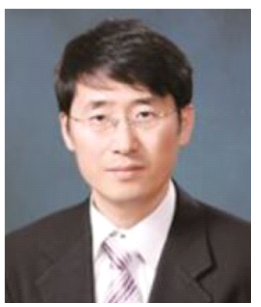

1993년 2월: 포항공과대학교 전자전기공 학과 (공학사)

1995년 2월: 포항공과대학교 전자전기공 학과 (공학석사)

1999년 2월 현재: 포항공과대학교 전자 전기공학과 (공학박사)

1999년 3월 현재: 한동대학교 전산전자

공학부 정교수

[주 관심분야] 센서네트워크 개발, RFID, 무선 송수신용 RF/

Analog IC 설계, 무선통신용 모뎀 설계, RF 전력증폭기 개발

임 창 헌[부경대학교/교수]

https://orcid.org/0000-0001-7022-8914

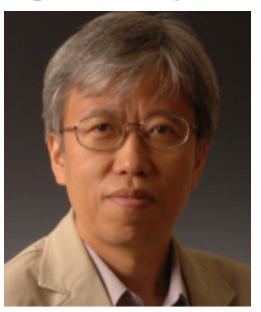

1986년 2월 서울대학교 전자공학과 (공학사)

1988년 8월 한국과학기술원 전기 및 전자

공학과 (공학석사)

1993년 8월 한국과학기술원 전기 및 전자 공학과 (공학박사)

1994년 8월 현재 부경대학교 전자공학과 교수

[주 관심분야] 간섭 분석, 주파수 공유
Annual International Symposium on Personal, Indoor, and Mobile Radio Communications(PIMRC), Montreal, QC, 2017, pp. 1-7.

[14] Q. Cheng, Z. Shi, D. N. Nguyen, and E. Dutkiewicz, "Non-cooperative OFDM spectrum sensing using deep learning," in 2020 International Conference on Computing, Networking and Communications(ICNC), Big Island, HI, 2020, pp. 704-708.

\section{김 창 주[한동대학교/교수]}

https://orcid.org/0000-0002-3689-8137

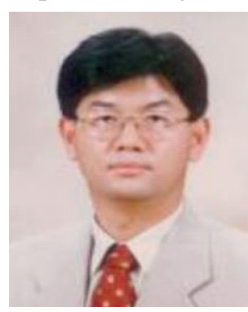

1993년 2월: 한국과학기술원 (공학박사) 1979년 12월 1983년 3월: ADD 연구원 1983년 3월 2018년 12월: ETRI 책임연구원 2018년 12월 현재: ETRI 연구전문위원 2019년 3월 현재: 한동대학교 초빙교수 1999년 2월 2001년 4월: ETRI 이동통신 모뎀연구부장

2003년 2월 2010년 12월: ETRI 전파기술연구부장

[주 관심분야] 이동통신, 무선통신, Cognitive Radio 등

\section{조 윤 석[한동대학교/교수]}

https://orcid.org/0000-0002-7166-6390

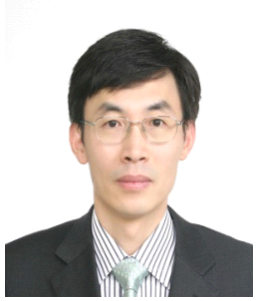

1987년 2월: 경북대학교 전자공학과 (공학 사)

1989년 2월: 한국과학기술원 전기및전자 공학과 (공학석사)

1994년 2월 현재: 한국과학기술원 전기

및 전자공학과 (공학박사)

1994년 3월 현재: 한동대학교 전산전자 공학부 교수

[주 관심분야] 신호처리, 임베디드시스템 